Abstract-To determine the most suitable aging structure for sturgeons, band counts of transverse sections of otoliths and the pectoral-, dorsal-, pelvic-, and anal-fin rays of Gulf sturgeon (Acipenser oxyrinchus desotoi) were compared. The otoliths and dorsal-, pelvic- and anal-fin rays produced inconsistent band patterns, but bands formed in the first (fin spine) and second marginal pectoral-fin rays were easily read and the most consistent. The index of average percent error and the coefficient of variation between final ages from the fin spines and the second marginal fin ray were $0.75 \%$ and $1.06 \%$, respectfully. Percent agreement between the assigned age of the fin spine and second marginal fin ray was high. The fin spine is commonly used to age sturgeon species; however, removal of the fin spine was considered potentially deleterious, especially to larger sturgeon. Sampling the second marginal fin ray appeared to be less harmful. Annual band formation in the second marginal fin ray for 3 Gulf sturgeon was validated with the use of oxytetracycline. We propose the second marginal pectoral-fin ray as an acceptable and less harmful alternative structure to the fin spine for aging Gulf sturgeon and recommend its use for other threatened and endangered sturgeon species. An extraction method of minimal invasiveness is presented here for field removal of the second marginal pectoral-fin ray from live sturgeon.

Manuscript submitted 2 July 2013. Manuscript accepted 30 July 2014. Fish. Bull. 112:274-282 (2014). doi:10.7755/FB.112.4.4

The views and opinions expressed or implied in this article are those of the author (or authors) and do not necessarily reflect the position of the National Marine Fisheries Service, NOAA.

\title{
A validated, minimally deleterious method for aging sturgeon
}

\author{
Ivy E. Baremore (contact author) \\ J. Drew Rosati
}

Email address for contact author: ivalina1@gmail.com

Panama City Laboratory

Southeast Fisheries Science Center

National Marine Fisheries Service, NOAA

3500 Delwood Beach Road

Panama City, Florida 32408

Present address for contact author: MarAlliance

P.O. Box 283

San Pedro, Ambergris Caye

Belize, Central America

Many sturgeon species are prized for their meat and caviar, and heavy fishing effort during the $19^{\text {th }}$ century greatly reduced population sizes around the world (Birstein, 1993). Of the 26 sturgeon species assessed by the International Union for Conservation of Nature and Natural Resources and listed on the IUCN Red List of Threatened Species, 18 (69\%) are listed as endangered or critically endangered (vers. 2012.2, http:// www.iucnredlist.org, accessed March 2013). Additionally, 20 of these species are listed as decreasing in population: only 4 sturgeon species are listed as increasing or stable and 2 have unknown population trends. North America is home to 9 species of sturgeon, 8 of which are listed as threatened or endangered under the U.S. Endangered Species Act (U.S. Fish and Wildlife Service, Species Reports, Environmental Conservation Online System, http://ecos.fws. gov/tess_public, accessed March 2013; NMFS'1): shortnose (Acipenser brevirostrum), green (A. medirostris), Atlantic (A. oxyrinchus), Gulf (A. oxyrinchus desotoi), white (A. transmontanus), pallid (Scaphirhynchus albus), shovelnose (S. platorynchus),

${ }^{1}$ NMFS (National Marine Fisheries Service). 2013. Endangered and threatened marine and ana-dromous fish. [Available from http://www.nmfs.noaa. gov/pr/species/esa/fish.htm, accessed March 2013.]. and Alabama (S. suttkusi). Sturgeon generally exhibit slow growth and late maturation-life history characteristics that make populations slow to recover from exploitation. Moreover, these life history traits, as well as habitat issues, equate to a difficult recovery process.

Age estimates of several species of sturgeon in North America have been evaluated by removing and observing the banding patterns of calcified structures, such as the first marginal pectoral-fin ray, otoliths, scutes, opercula, and sphenoids (Brennan and Cailliet, 1989; Nakamoto et al. ${ }^{2}$; Rossiter et al., 1995; Stevenson and Secor, 1999; Hurley et al., 2004; Jackson et al., 2007; Bruch et al., 2009). Although it is not a true spine, the first marginal pectoral-fin ray of sturgeons commonly is called the fin spine, and hereafter it will be referred to as such in this article. All structures except the fin spine have proved to be detrimental to or have required sacrifice of the fish (Brennan and Cailliet, 1989); therefore, the most widely used aging structure for sturgeon species is the fin

\footnotetext{
2 Nakamoto, R. J., T. T. Kisanuki, and G. H. Goldsmith. 1995. Age and growth of Klamath River green sturgeon (Acipenser medirostris). U.S. Fish and Wildlife Service Project \# 93-FP-13, 20 p. [Available from Yreka Fish and Wildlife Office, U.S. Fish and Wildlife Serice, 1829 South Oregon St., Yreka, CA 96097.]
} 


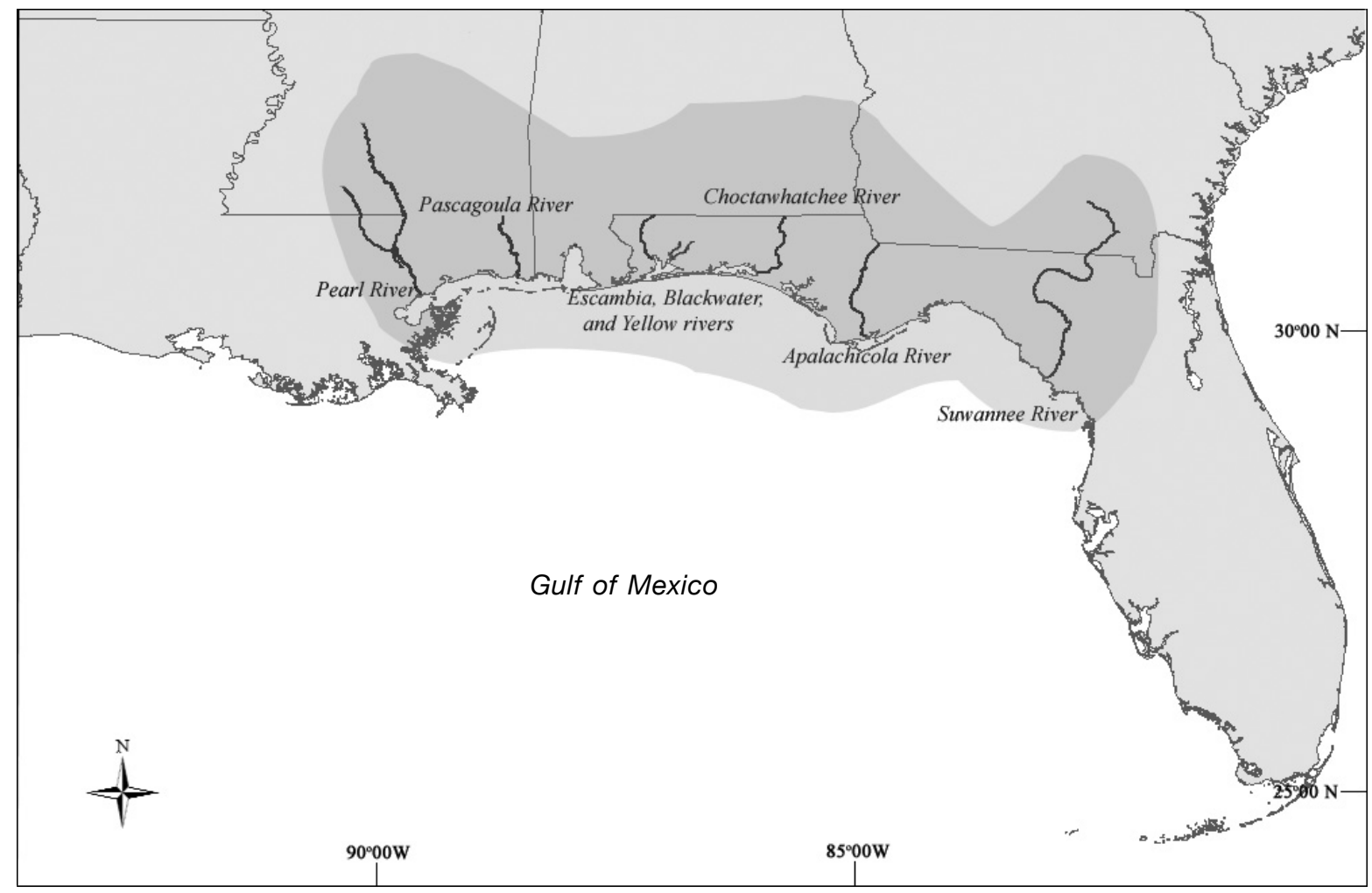

Figure 1

The approximate range (the shaded area) and major spawning rivers of Gulf sturgeon (Acipenser oxyrinchus desotoi) in the Gulf of Mexico. Structures for aging Gulf sturgeon were collected from sturgeon captured in the Choctawhatchee River in 2010, from archived specimens from the Apalachicola and Choctwahatchee rivers in 2010, and from an archive of Gulf sturgeon captured on the Suwannee River in 1980-90.

spine (Rien and Beamesderfer, 1994; Rossiter et al., 1995; Stevenson and Secor, 1999; Berg, 2004; Hurley et al., 2004; Whiteman et al., 2004; Allen et al., 2009). Kahn and Mohead (2010) advised against the use of the fin spine in mature shortnose, Atlantic, Gulf, and green sturgeon because of increased reader error, abnormal regrowth, and an increased chance of deleterious effects. To reduce harm to endangered and threatened species and to increase standardization for aging protocols, options other than the fin spine should be developed.

Another important aspect of age and growth that is often ignored is the validation of annual band formation in aging structures (Beamish and McFarlane, 1983; Campana, 2001). Despite the widespread use of the pectoral spine for age estimation (Rien and Beamesderfer, 1994; Rossiter et al., 1995; Morrow et al., 1998; Stevenson and Secor, 1999; Hurley et al., 2004; Whiteman et al., 2004), successful validation of annual band formation in the pectoral spine has been published for only 2 North American sturgeon species: white (Rien and Beamesderfer, 1994) and lake (Rossiter et al., 1995) sturgeon. Accurate age estimation is critical because it forms the basis for calculating growth and mortality rates, age at maturity, and estimates of longevity, all of which are essential for the production of accurate population models.

For this study, we had the following objectives: 1) to evaluate and compare banding patterns from the pectoral spines, fin rays, and otoliths of Gulf sturgeon; 2) to determine which aging structure, for which removal is nonlethal and minimally deleterious, provides the most accurate and consistent band counts; 3 ) to validate the frequency of band formation within the preferred aging structure; and 4) to provide the field and laboratory methods to remove, process, and interpret the validated aging structure for Gulf sturgeon.

\section{Materials and methods}

\section{Sampling protocol}

To determine the best aging structure for Gulf sturgeon, 14 frozen Gulf sturgeon from previous mortality events on the Choctawhatchee and Apalachicola rivers (Fig. 1) were sampled in 2010. The fin spine, second marginal pectoral-fin ray (the fin ray just posterior to the fin spine), pectoral-, dorsal-, pelvic-, and anal-fin rays, and sagittal otoliths were removed, cleaned, and 
sectioned to determine the most suitable aging structure for Gulf sturgeon. Additionally, an archive of airdried fin spines from Gulf sturgeon collected on the Suwannee River in 1980-90 was donated for inclusion in future age and growth analysis (K. Sulak, U.S. Geological Survey). Fin spines from sturgeon collected in the Pascagoula River likewise were processed for future studies (M. Peterson, Univ. Southern Mississippi). In many cases, the second marginal pectoral-fin ray was sampled along with the fin spine: these samples were used to compare band counts between these structures.

\section{Processing of structures}

Fin spines, fin rays, and otoliths The entire left pectoral, left pelvic, dorsal, and anal fins were removed at the point of articulation from each of the 14 archived Gulf sturgeon. With a scalpel, the fin spine and approximately 5 leading marginal rays were isolated from each fin. Excess tissue was removed from between each hemitrich of the fin rays with a stiff brush and forceps. In extreme cases, samples were boiled (2-5 min) to ease cleaning. Air-dried fin rays and small, fragile spines $(<5 \mathrm{~mm}$ in diameter) were mounted in Loctite $0151 \mathrm{Hysol}^{3}$ epoxy (Henkel Corp., Rocky Hill, CT) and allowed to harden for 24 hours. Large fin spines ( $>5$ $\mathrm{mm}$ in diameter) were not mounted in epoxy because of their rigid nature; to simplify mounting and obtain the best sections, the articulating process of the fin spine was removed by using a Hillquist Thin Section Machine (Hillquist Inc., Denver).

Through the use of an IsoMet low speed saw (Buehler, Lake Bluff, IL) with a Norton grinding wheel (Saint-Gobain, Courbevoie, France), a minimum of 3 transverse sections approximately $0.3-0.6 \mathrm{~mm}$ thick were made starting at the proximal end of the fin spine or ray. Sections were mounted on microscope slides with the clear mounting medium Cytoseal (Thomas Scientific, Swedesboro, NJ) and examined under a dissecting microscope at magnifications of $10-75 \times$ that varied depending on the size of the section. Transmitted or reflected light was used on the basis of which one best elucidated band formations. Digital images of each section were taken with a MicroPublisher 5.0 real-time viewing camera (QImaging, Surrey, Canada) mounted on an RZ Series CMO stereo microscope (Meiji Techno America, Santa Clara, CA). Growth bands were counted by using standard aging methods (Brennan and Cailliet, 1989; Morrow et al., 1998; Stevenson and Secor, 1999), whereby a band pair consisted of one opaque and one translucent ring that was continuous around the section.

Both sagittal otoliths were removed from the 14 archived Gulf sturgeon, cleaned in fresh water, and allowed to air dry. One otolith from each sturgeon was

\footnotetext{
${ }^{3}$ Mention of trade names or commercial companies is for identification purposes only and does not imply endorsement by the National Marine Fisheries Service, NOAA.
}

mounted in 2 Ton Epoxy (ITW Devcon, Danvers, MA) and sectioned according to Bruch et al (2009). Sections $(0.5 \mathrm{~mm})$ were mounted on a microscope slide with $\mathrm{Cy}$ toseal mounting medium. Digital images were taken of each otolith section according to the method described previously for fin rays. The second whole otolith was stored dry and archived.

Each structure was evaluated qualitatively on the basis of 3 criteria: 1) invasiveness of the removal; 2) practicality of sampling in the field; and 3) consistency and clarity of the banding pattern. The structure for which removal was the least harmful, while also providing consistent banding patterns, was considered the "best" aging structure for Gulf sturgeon.

Precision and bias To measure reproducibility and test whether the second marginal pectoral-fin ray was a comparable aging structure to the commonly used fin spine, average percent error (APE) (Beamish and Fournier, 1981) between band counts for each structure was calculated when both were available:

$$
A P E_{\mathrm{j}}=100 \% \times \frac{1}{R} \sum_{i=1}^{R} \frac{\left|X_{\mathrm{ij}}-X_{\mathrm{j}}\right|}{X_{\mathrm{j}}},
$$

where $X_{\mathrm{ij}}=$ the $i$ th age determination of the $j$ th fish; $X_{j}=$ the mean age of the $j$ th fish; and $R=$ the number of times each fish was aged.

Age estimates between the fin ray and fin spine were measured for precision with the coefficient of variation (CV) (Chang, 1982):

$$
C V_{\mathrm{j}}=100 \% \times \frac{\sqrt{\sum_{i=1}^{R} \frac{\left[X_{\mathrm{ij}}-X_{\mathrm{j}}\right]^{2}}{X_{\mathrm{j}}}}}{X_{\mathrm{j}}},
$$

where $C V_{\mathrm{j}}=$ the age precision estimate for the $j$ th fish.

Average percent error was calculated for each fish for which samples of both a fin spine and a second marginal fin ray existed, and the results were presented as an index. Similarly, CV was averaged across all samples to produce a mean value. Percent agreement (PA) of age estimates from fin rays and fin spines was also calculated. Gulf sturgeon without a fully formed band pair (band count $=0$ ) were not included in analyses because their inclusion artificially inflated the APE, and CV could not be calculated for those fish. Precision and bias of band counts for each structure was examined by using a 1:1 bias plot.

Field proofing After the best aging structure had been determined, a protocol was developed for removal of fin rays from live sturgeon. Fin rays were collected opportunistically from Gulf sturgeon during ongoing collaborative gillnet surveys conducted by researchers from Delaware State University, the University of Southern 
Mississippi, and the U.S. Fish and Wildlife Service. Fork length (FL), total length (TL), and weight of each sturgeon were recorded in centimeters and kilograms, respectively, as part of these surveys. Collection of fin rays primarily occurred in the fall months, and samples were collected on the Yellow, Choctawhatchee, and Apalachicola rivers from September 2010 through early November 2012.

Validation of aging structure As part of the standardized sampling practices used for ongoing collaborative surveys, approximately 100 Gulf sturgeon received a dose of $10 \mathrm{mg}$ of oxytetracycline (OTC) per kilogram of body weight, which was injected intramuscularly (Baremore and Rosati, 2011). An aging structure from each recaptured, OTC-injected Gulf sturgeon was removed and sectioned according to the methods described previously. These sections were then viewed under a dissecting microscope with reflected UV light to illuminate any potential chemical mark that the injected OTC had incorporated within the structure. The placement of the chemical mark was evaluated in comparison with subsequently formed band pairs and with time at large to determine frequency of band formation.

\section{Results}

\section{Sampling protocol}

Fin spines Removal of fin spines was considered to be invasive and possibly harmful to the fish because of bleeding, potential for the incised spine to snag in debris, and loss of hydrodynamics while swimming. The practicality of removal in the field was somewhat limited, especially for Gulf sturgeon $>120 \mathrm{~cm} \mathrm{FL}$, because a large hack saw was generally required. The banding pattern was consistent until about 15 band pairs were counted, a threshold after which band pairs often were compressed and reading bands became difficult (Fig. 2A). In many cases, the second marginal fin ray was incorporated in the spine, an occurrence that could obscure bands and make band counts less reliable. Because of their historic use and mostly clear banding patterns, fin spines were not excluded as an aging structure; however, they were considered not ideal for aging live sturgeon.

Fin rays: dorsal, pelvic, and anal Removal of dorsal-, pelvic-, and anal-fin rays from Gulf sturgeon was minimally invasive; these fin rays were small and not rigidly structured and could be removed easily. The required tools for removal were a scalpel, forceps, and wire cutters. Once sectioned, banding patterns were visible; however, bands were indistinct and inconsistent in relation to the other structures (for image of dorsal-fin rays, see Fig. 2B). Although easy to remove and not harmful to the sturgeon, these fin rays were excluded as aging structures because of the lack of clarity of the bands.
Otoliths Otolith removal was maximally invasive because of their location in the head and could only be performed on mortalities. Otoliths were also very difficult to retrieve because of the bony structure and size of Gulf sturgeon. Band pairs could be difficult to distinguish and were inconsistent among individuals; therefore, band counts could not be quantified for this structure (Fig. 2C). The use of otoliths for aging Gulf sturgeon was determined to be neither feasible nor acceptable for a threatened species.

Second marginal pectoral-fin ray The second marginal pectoral-fin ray was larger and more rigidly structured than the fin rays from other fins of Gulf sturgeon. Although removal of this fin ray was slightly more invasive because of its size, the effect of its removal on the sturgeon was considered to be negligible. The removal of this fin ray was relatively easy in the field and required the same tools as the other fin rays. Furthermore, band formation was mostly clear and consistent for the majority of samples (Fig. 2D). Therefore, on the basis of our established criteria, the second marginal pectoral-fin ray was chosen as the best structure for aging Gulf sturgeon.

Removal of the second marginal fin ray was simple and could be completed by an experienced biologist in less than $1 \mathrm{~min}$. The tools necessary for removal were small, inexpensive, and portable-notable differences in comparison with the hacksaw that was often required for the removal of fin spines. The second marginal fin rays of Gulf sturgeon $>150 \mathrm{~cm}$ FL were more difficult to remove and often required a larger initial incision because of the diameter of the fin ray. The edges were often fractured from the force required to excise the sample, but the fin ray generally could be salvaged if the removed segment was at least $2 \mathrm{~cm}$ in length.

Captured Gulf sturgeon were placed in a holding tank with their ventral surface facing up. A size 10 scalpel was used to make a parallel cut on each side of the second marginal pectoral-fin ray approximately 2.5 $\mathrm{cm}$ away from the point of articulation. This process acted to separate the second marginal fin ray from the spine and third marginal fin ray while allowing us to avoid major blood vessels. Wire cutters were then used to free the segment $(1.0-1.5 \mathrm{~cm})$ by snipping each end of the parallel cut. The fin ray segment was removed with forceps, and a mixture of Betadine antiseptic solution (Purdue Products, Stamford, CT) and petroleum jelly was placed over the site for prophylactic purposes. Sampled fin rays were placed in labeled paper or plastic bags and allowed to air dry before processing. Several Gulf sturgeon that were sampled for age analysis were recaptured up to 6 months after the initial capture to assess healing of the fin.

Bleeding at the site of the incision was common but was generally minimal and stopped within 5 min of the cessation of the procedure. Recaptured individuals were healed completely 6 months after fin removal, and the fin showed less irritation at the removal site than 


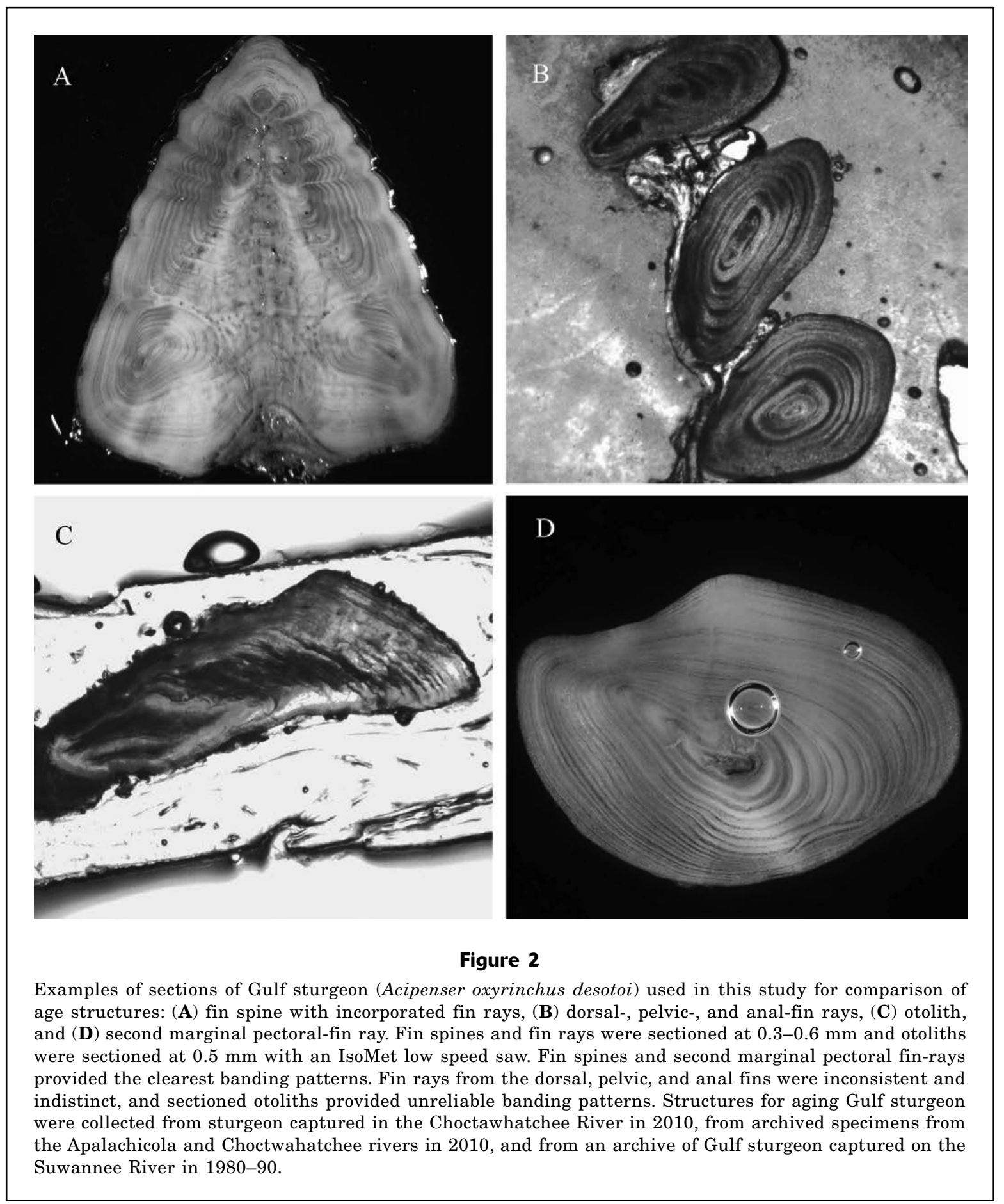

did those fins with commonly applied external tags (Fig. 3, A and B). Removal sites were healed dramatically in comparison with the sites where fin spines had been sampled (Fig. 3C).

Overall, the second marginal fin ray produced consistent, clear, and reliable banding patterns. Band count comparisons between the second marginal fin ray and fin spine showed little systematic bias between the structures for counts of up to 25 bands (Fig. 4). Precision and PA estimates were high for band counts between the fin spine and second marginal fin ray: $n=222$; $\mathrm{CV}=0.75 \%$; $\mathrm{APE}=1.06 \% ; \mathrm{PA}=96.46 \%( \pm 0$ band pairs $)$, 98.23\% ( \pm 1 band pair), and $100.00 \%$ ( \pm 2 band pairs). Therefore, the second marginal fin ray was considered a robust aging structure and appears to be a valid substitute for the fin spine for aging analysis. 

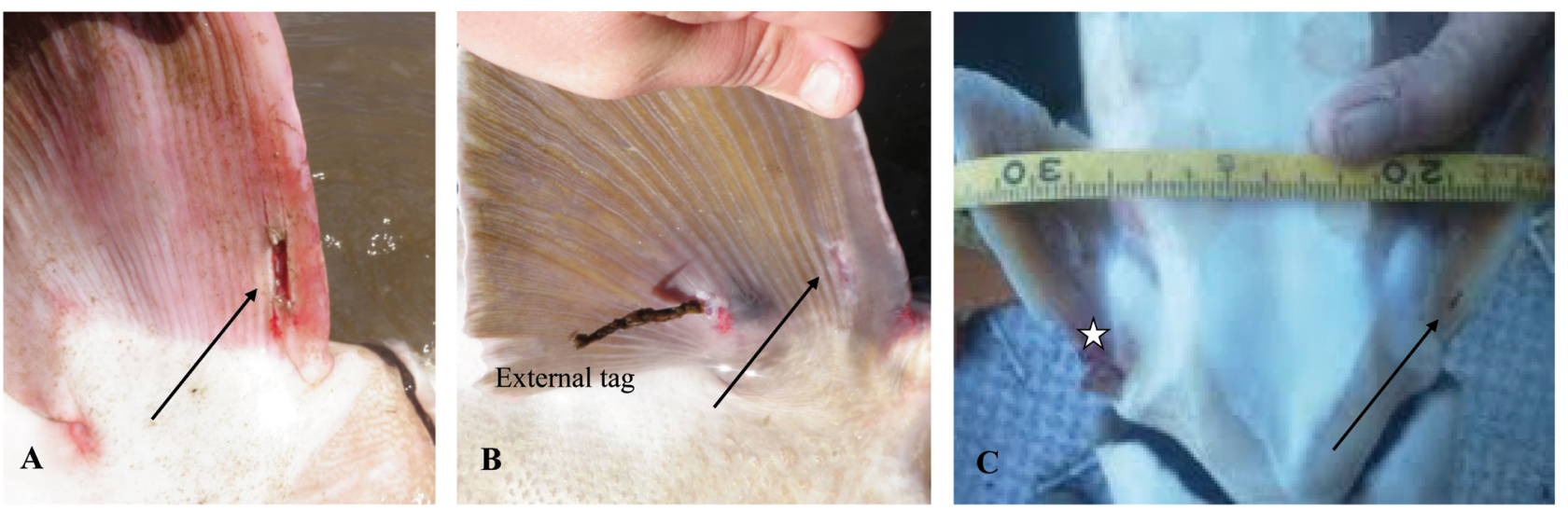

Figure 3

Ventral surface of Gulf sturgeon (Acipenser oxyrinchus desotoi) pectoral fins (A) just after removal of a segment of the second marginal pectoral-fin ray, (B) 6 months after removal of that segment, and (C) immediately after removal of the right fin spine and left second marginal fin ray. An arrow in each panel indicates the place where the second marginal fin ray was removed, and the star in the final panel marks the site of the fin spine removal. Second marginal pectoral-fin rays were removed from live Gulf sturgeon in the Choctawhatchee and Apalachicola rivers during 2010, and these photos indicate that removal of this fin ray is less invasive than removal of fin spines.

\section{Validation of aging structure}

Annual band formation was validated for 3 Gulf sturgeon that were recaptured one year after being marked with OTC and for 1 Gulf sturgeon that was recaptured after 6 months. Visual assessment of the sections showed that, for sturgeon with 6,7 , and 8 total band pairs, 1 band pair was fully formed after the chemical mark from the OTC injection (Fig. 5). A Gulf sturgeon recaptured in October after being injected in Febru- 


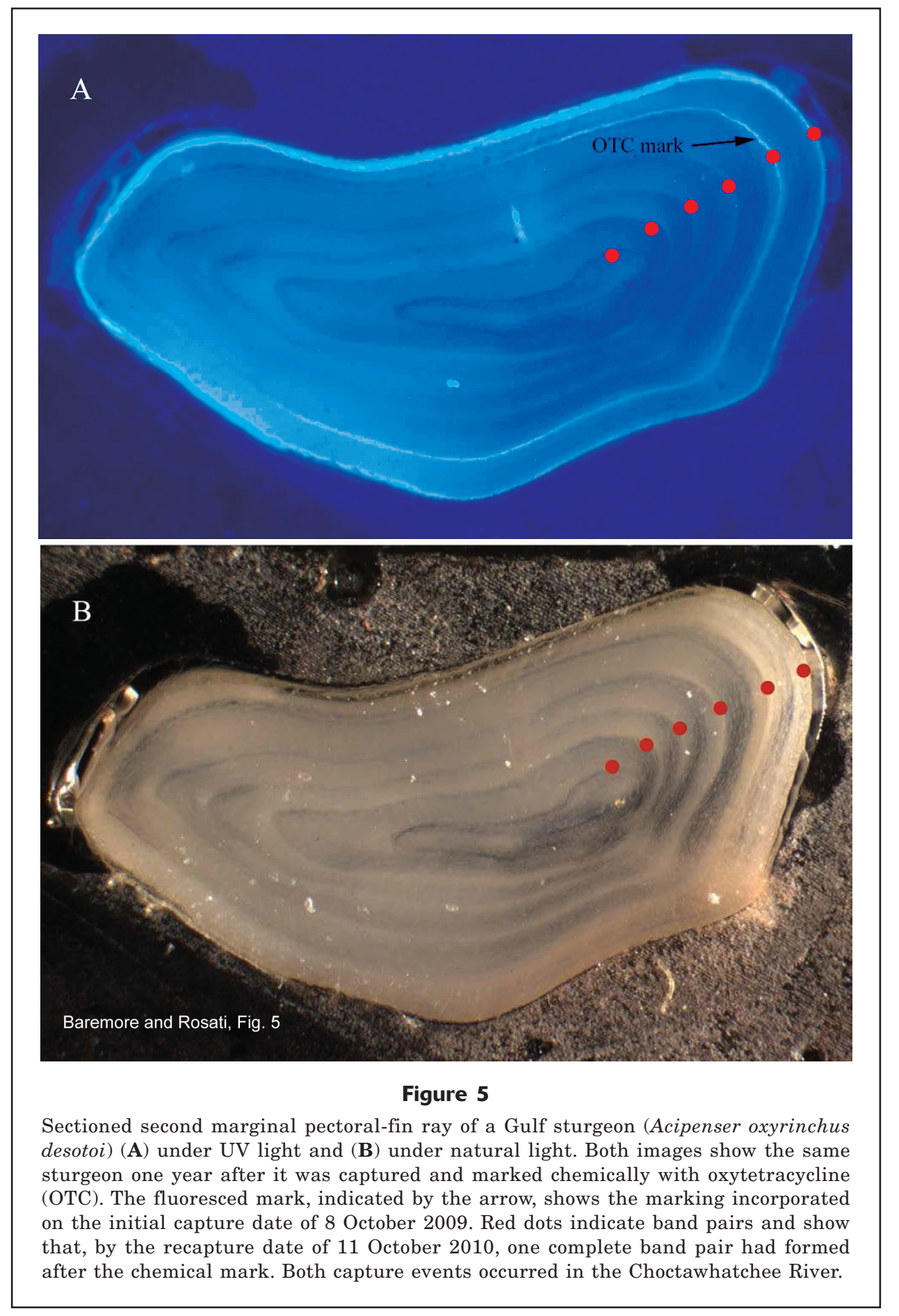

ary of that year had 15 band pairs; a partially formed, translucent band was evident after the chemical mark. However, fin rays from 8 other recaptured sturgeon did not fluoresce under UV light. This outcome indicates that OTC was not incorporated into the bony structures of many of the Gulf sturgeon that were injected with it and that doses may have been too low for validation purposes.

\section{Discussion}

The second marginal pectoral-fin ray is not an unknown structure for age and growth studies, although its use as a primary aging structure has not been discussed previously. Brennan and Cailliet (1989) noted that bands from this fin ray were consistent with the bands from fin spines but did not evalu- 
ate the use of this fin ray as an aging structure. We found that the second marginal fin ray was simple to remove and that sections provided reliable and clear band counts.

Otoliths and fin spines are commonly used to age fishes-fin spines being the most prevalent for sturgeon species (Huff ${ }^{4}$; Brennan and Cailliet, 1991; Rossiter et al., 1995; Stevenson and Secor, 1999; Everett et al., 2003). Although otoliths often are considered the best structure for aging fish (Casselman, 1987; Campana, 2001), band formation in otoliths of Gulf sturgeon was unreliable and difficult to interpret. Similar difficulties have been noted for other sturgeon species (Brennan and Cailliet, 1989); however, bomb radiocarbon dating has been used to validate band formation for 46 otoliths of lake sturgeon (Bruch et al., 2009). Fin spines provide mostly clear and interpretable banding patterns, and their use has been validated for several species (Rien and Beamesderfer, 1994; Rossiter et al., 1995), but their removal has been discouraged for threatened and endangered sturgeon species because of the possibility of deleterious effects (Kahn and Mohead, 2010).

Although our precision and PA estimates were very high for band counts between the fin spine and second marginal fin ray, our age assignments could have been somewhat biased by the methods used. Because the fin spine and second marginal fin ray were often on the same slide, band counts were made in conjunction with both structures, rather than independent of each structure. Future comparative studies should randomize the order in which fin rays and spines are read.

Of the Gulf sturgeon that previously had been injected with OTC, 12 were recaptured and sampled over the course of this study. However, formation of annual bands in the second marginal fin ray was validated for only 3 of those Gulf sturgeon. Ages could not be validated for the other recaptured Gulf sturgeons because OTC injections failed to produce a chemical mark in 8 of those fish. This low rate of OTC incorporation may have been due to the methods used: Rien and Beamesderfer (1994) reported a $98 \%$ detection rate of OTC chemical marks in the fin spines of white sturgeon when they used a concentration of $25 \mathrm{mg} / \mathrm{kg}$ and Rossiter et al. (1995) used a dose of $35 \mathrm{mg} / \mathrm{kg}$ to validate band formation in lake sturgeon. The use of a dose of $10 \mathrm{mg} / \mathrm{kg}$ in our study likely led to the high failure rate, and future validation studies for sturgeon species should use at least $25 \mathrm{mg} / \mathrm{kg}$. Loss of OTC at the injection site was also noted; therefore, a slow injection followed by pressure applied to the site is recommended as well. Despite the low detection rate, we feel confi-

\footnotetext{
${ }^{4}$ Huff, J. A. 1975. Life history of Gulf of Mexico sturgeon, Acipenser oxyrhynchus desotoi, in the Suwannee River, Florida. Florida Marine Research Publications 16, 32 p. Marine Research Laboratory, Florida Department of Natural Resources, St. Petersburg, FL. [Available from http://f50006a. eos-intl.net/ELIBSQL12_F50006A_Documents/FMRP016ocr. pdf.]
}

dent that band pairs in the second marginal fin rays are annual marks.

Although the set of methods used in this study was developed for Gulf sturgeon, it likely is widely applicable to other sturgeon species worldwide. Researchers have advised that caution be taken when the fin spine is used to age sturgeon because of difficulty with identification of growth bands (Hurley et al., 2004; Jackson et al., 2007) and because of the potentially harmful effects of removing the fin spine from large individuals (Kahn and Morehead, 2010). Additionally, the use of the second marginal fin ray may also be appropriate for species related to sturgeon, such as paddlefish. Accurate life history information is crucial for the development of population assessments and recovery plans but can be difficult to obtain for threatened and endangered species. The simple, field-ready methods described in this article can easily be adapted or modified to suit ongoing monitoring programs of sturgeon and can be used to improve population assessments for these data-limited species.

\section{Conclusions}

The second marginal pectoral-fin ray provided an excellent alternative to fin spines for aging Gulf sturgeon. Removal was minimally deleterious, and the banding pattern was generally clear and consistent. Annual band formation was validated for 3 Gulf sturgeon with 6,7 , and 8 band pairs, but $10 \mathrm{mg} / \mathrm{kg}$ is too low a dose of OTC to reliably mark calcified structures of Gulf sturgeon. A dose of $25 \mathrm{mg} / \mathrm{kg}$ is recommended for future validation studies. The methods described in this article have wide applicability to other sturgeon species and are important for population assessment of these overexploited fishes.

\section{Acknowledgments}

Many researchers contributed expertise and samples, but we would especially like to thank D. Fox, K. Fleming, N. Willett, and F. Parauka for providing samples and field time. K. Sulak donated an archive of spines and fin rays, and M. Peterson, J. Havrylkoff, and T. Slack provided samples as well. C. Fioramonti, R. Allman, and C. Palmer lent advice and laboratory equipment, for which we are very grateful. We also thank S. Bolden and G. Davenport for giving us the opportunity to work with this species.

\section{Literature cited}

Allen, P. J., J. A. Hobbs, J. J. Cech Jr., J. P. Van Eenennaam, and S. I. Doroshov.

2009. Using trace elements in pectoral fin rays to assess life history movements in sturgeon: estimating age 
at initial seawater entry in Klamath River green sturgeon. Trans. Am. Fish. Soc. 138:240-250.

Baremore, I. E., and J. D. Rosati.

2011. Gulf sturgeon standardized abundance and mortality study: year one report. NOAA Tech. Memo. NMFS-SEFSC-619, $34 \mathrm{p}$.

Beamish, R. J., and D. A. Fournier.

1981. A method for comparing the precision of a set of age determinations. Can. J. Fish. Aquat. Sci. 38:982-983.

Beamish, R. J., and G. A. McFarlane.

1983. The forgotten requirement for age validation in fisheries biology. Trans. Am. Fish. Soc. 112:735-743.

Berg, J. J.

2004. Population assessment of the Gulf of Mexico sturgeon in the Yellow River, Florida. M.S. thesis, 86 p. Univ. Florida, Gainesville, FL.

Birstein, V. J.

1993. Sturgeons and paddlefishes: threatened fishes in need of conservation. Conserv. Biol. 7:773-787.

Brennan, J. S., and G. M. Cailliet.

1989. Comparative age-determination techniques for white sturgeon in California. Trans. Am. Fish. Soc. 118:296-310.

1991. Age determination and validation studies of white sturgeon, Acipenser transmontanus, in California. In Acipenser: actes du premier colloque international sur l'esturgeon; Bordeaux, France, October 3-6, 1989 (P. Williot, ed.), p. 209-234. CEMAGREF-DICOVA, Antony, France.

Bruch, R. M., S. E. Campana, S. L. Davis-Foust, M. J. Hansen, and J. Janssen.

2009. Lake sturgeon age validation using bomb radiocarbon and known-age fish. Trans. Am. Fish. Soc. 138:361-372.

Campana, S. E.

2001. Accuracy, precision and quality control in age determination, including a review of the use and abuse of age validation methods. J. Fish Biol. 59:197-242.

Casselman, J. M.

1987. Determination of age and growth. In The biology of fish growth (A. H. Weatherley and H. S. Gill, eds.), p. 209-242. Academic Press, London.

Chang, W. Y. B.

1982. A statistical method for evaluating the reproducibility of age determination. Can. J. Fish. Aquat. Sci. 39:1208-1210.

Everett, S. R., D. L. Scarnecchia, G. J. Power, and C. J. Williams.

2003. Comparison of age and growth of shovelnose sturgeon in the Missouri and Yellowstone rivers. N. Am. J. Fish. Manage. 23:230-240.

Hurley, K. L., R. J. Sheehan, and R. C. Heidinger.

2004. Accuracy and precision of age estimates for pallid sturgeon from pectoral fin rays. N. Am. J. Fish. Manage. 24:715-718.

Jackson, N., J. Garvey, and R. Colombo.

2007. Comparing aging precision of calcified structures in shovelnose sturgeon. J. Appl. Ichthyol. 23:525-528.

Kahn, J., and M. Mohead.

2010. A protocol for use of shortnose, Atlantic, Gulf, and green sturgeons. NOAA Tech. Memo. NMFS-OPR-45, $62 \mathrm{p}$.

Morrow, J. V., Jr., J. P. Kirk, K. J. Killgore, and S. G. George. 1998. Age, growth, and mortality of shovelnose sturgeon in the lower Mississippi River. N. Am. J. Fish. Manage. 18:725-730.

Rien, T. A., and R. C. Beamesderfer.

1994. Accuracy and precision of white sturgeon age estimates from pectoral fin rays. Trans. Am. Fish. Soc. 123:255-265.

Rossiter, A., D. L. G. Noakes, and F. W. H. Beamish. 1995. Validation of age estimation for the lake sturgeon. Trans. Am. Fish. Soc. 124:777-781.

Stevenson, J. T., and D. H. Secor.

1999. Age determination and growth of Hudson River Atlantic sturgeon, Acipenser oxyrinchus. Fish. Bull. 98:153-166.

Whiteman, K., V. H. Travnichek, M. L. Wildhaber, A. DeLonay, D. Papoulias, and D. Tillett.

2004. Age estimation for shovelnose sturgeon: a cautionary note based on annulus formation in pectoral fin rays. N. Am. J. Fish. Manage. 24:731-734. 